\title{
Bioactive properties of Sanguisorba minor L. cultivated in central Greece under different fertilization regimes
}

\author{
Tiane C. Finimundy ${ }^{\mathrm{a}, \mathrm{b}}$, Anestis Karkanis ${ }^{\mathrm{c}}$, Ângela Fernandes ${ }^{\mathrm{a}}$, Spyridon A. Petropoulos ${ }^{\mathrm{c}, *}$, \\ Ricardo Calhelha $^{\mathrm{a}}$, Jovana Petrović ${ }^{\mathrm{d}}$, Marina Soković ${ }^{\mathrm{d}}$, Eduardo Rosa $^{\mathrm{b}}$, Lillian Barros ${ }^{\mathrm{a}}$, \\ Isabel C.F.R. Ferreira ${ }^{a}$

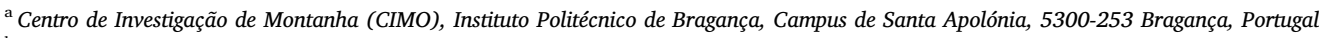 \\ ${ }^{\mathrm{b}}$ CITAB - University of Trás-os-Montes and Alto Douro (UTAD), Department of Agronomy, Vila Real, Portugal \\ ${ }^{c}$ Department of Agriculture Crop Production and Rural Environment, University of Thessaly, Fytokou Street, 38446 Volos, Greece \\ ${ }^{\mathrm{d}}$ Institute for Biological Research "Siniša Stanković", National Institute of Republic of Serbia, University of Belgrade, Bulevar Despota Stefana 142, 11000 Belgrade, Serbia
}

\section{A R T I C L E I N F O}

\section{Keywords:}

Antimicrobial activities

Ellagitannins

Fertilization

Flavonoids

Phenolic acids

Sanguisorba minor L.

Small burnet

Tannins

\begin{abstract}
A B S T R A C T
In this study, the chemical characterization and bioactive properties of $S$. minor cultivated under different fertilization rates (control, half rate and full rate) were evaluated. Twenty-two phenolic compounds were identified, including five phenolic acids, seven flavonoids and ten tannins. Hydrolysable tannins were prevalent, namely Sanguiin H-10, especially in leaves without fertilization (control). Roots of full-rate fertilizer (660 Kg/ha) presented the highest flavonoid content, mainly catechin and its isomers, whereas half-rate fertilizer ( $330 \mathrm{Kg} / \mathrm{ha})$, presented the highest content of total phenolic compounds, due to the higher amount of ellagitannins (lambertianin C: $84 \pm 1 \mathrm{mg} / \mathrm{g}$ of dry extract). Antimicrobial activities were also promising, especially against Salmonella typhimurium (MBC $=0.44 \mathrm{mg} / \mathrm{mL}$ ). Moreover, root samples revealed activity against all tested cell lines regardless of fertilization rate, whereas leaves were effective only against HeLa cell line. In conclusion, $S$. minor could be a source of natural bioactive compounds, while fertilization could increase phenolic compounds content.
\end{abstract}

\section{Introduction}

Sanguisorba genus belongs to the Rosaceae family, including several species of interest (Karkanis et al., 2014; Meng et al., 2018). The most representative and commonly used species of this genus are Sanguisorba minor Scop. (small burnet) and Sanguisorba officinalis L. (great burnet) which are native in the Mediterranean basin and other areas of the world (Gawron-Gzella et al., 2016; Karkanis et al., 2019). The leaves and roots of these species contain a wide variety of bioactive compounds such as gallic acid, ellagic acid, (+)-catechin, lambertianin C, sanguiin H-10, and ziyuglycoside II (Karkanis et al., 2019; Lkhagvasuren \& Kim, 2019; Tan et al., 2019; Zhu et al., 2019). So far, it has been well documented that isolated bioactive compounds and/or extracts of both species exert a broad spectrum of medicinal properties. In particular, in the recent study of Tan et al. (2019) it was reported that both the $S$. officinalis extracts and ellagic acid obtained after purification of plant extracts possess anticancer activity through the antiproliferation action against B16F10 melanoma cells. Moreover, ziyuglycoside II, the main phytochemical isolated from $S$. officinalis roots, exhibited anticancer activity by inducing apoptosis of HCT116 and SW480 human colon cancer cells (Lkhagvasuren \& Kim, 2019). Moreover, S. minor exhibited significant antioxidant activity which was correlated with the increased content in total phenolic compounds (Romojaro, Sanchez-Bel, Serrano, \& Pretel, 2013), while Romojaro et al. (2013) suggested the incorporation of $S$. minor leaves in vegetable oils as a means to increase their overall oxidative stability. In another study, Bedoya, Sanchez-Palomino, Abad, Bermejo, and Alcami (2001) reported that $S$. minor aqueous extracts possess anti-HIV activity at concentrations of $50 \mu \mathrm{g} / \mathrm{mL}$ through the inhibition of infections in MT-2 cells. Other effects of $S$. minor on human health include the antibacterial activity of root extracts against several bacteria, as reported by Karkanis et al. (2019).

Considering that the consumption of wild edible species may have beneficial health effects and diversify modern human diet, as well as the increasing market demands for healthy and functional foods, it is of major importance to suggest and introduce the commercial cultivation of these species (Karkanis et al., 2019; Petropoulos, Karkanis, Martins, \& Ferreira, 2016; Petropoulos, Fernandes, Tzortzakis et al., 2019).

\footnotetext{
* Corresponding authors.

E-mail addresses: spetropoulos@uth.gr (S.A. Petropoulos), iferreira@ipb.pt (I.C.F.R. Ferreira).
} 
Despite these recent trends, to the best of our knowledge, there is scarce literature on the suitability of $S$. minor to commercial cultivation conditions. The most common limitation for applying commercial cultivation practices to wild plants is associated with difficulties in plant propagation, although this problem does not exist in $S$. minor, since the species is easily sexually propagated with seeds. In particular, De Lillis, Manes, and Tufaro (2005) observed that seeds presented high germination rates $(89 \%)$ while Lenzi, Orlandini, Bulgari, Ferrante, and Bruschi (2019) reported slightly lower germination rates (75.5\%), a difference which could be attributed to different germination conditions (air temperature, photoperiod and relative humidity) (Azimi, Heshmati, Kianian, \& Jafari, 2016). Apart from growing conditions, sowing depth is critical to achieve high seedling emergence as reported by Burmeier, Donath, Otte, and Eckstein (2010). It was also observed that the highest seedling emergence of $S$. officinalis was recorded when seeds were sown at 1-2 cm deep, depending on sowing substrate (clay or sand). Moreover, Snowball, D'Antuono, Cohen, Gajda, and Bennett (2010) reported that $S$. minor performed well under field and nursery conditions showing high survival rates and seed production. Recently, Karkanis et al. (2019), studied the effects of the type of substrate on the growth, physiology and content of phenolic compounds in $S$. minor plants. They suggested that the use of commercially available plant growth substrates (peat and/or perlite) may increase the content of bioactive compounds and the functional properties of the species. Lenzi et al. (2019) also reported that $S$. minor is a promising species for the production of micro/baby greens for dietary purposes although specific attention should be given to cultivation conditions since they might induce a reduction of antinutritional factors (e.g. high nitrates and heavy metals content).

Considering the limited knowledge about the cultivation of $S$. minor, it is very important to reveal the effects of cultural practices such as plant density, irrigation, fertilization, harvesting stage, and weed management on plant growth. On the other hand, it was intended to stimulate the consumption of this plant-enhanced in bioactive compounds to diversify the modern human diet. Therefore, the aim of this study was to evaluate the effects of different rates of inorganic fertilization on plant growth, as a way to enhance the chemical composition and bioactive properties of $S$. minor plant tissues (leaves and roots).

\section{Material and methods}

\subsection{Plant material and sampling}

A pot experiment was carried out at the experimental farm of the University of Thessaly in Velestino, Greece. The experimental layout followed the completely randomised design (CRD) with fifteen replications (pots) per treatment. Small burnet seeds were sown on 2 March 2016 in $2 \mathrm{~L}$ pots filled with peat $\left(\mathrm{pH}\left(\mathrm{CaCl}_{2}\right)=5.5-6.5\right.$, salt content (KCl): $0.7-1.8 \mathrm{~g} / \mathrm{L}$, nutrients content: $80-280 \mathrm{mg} / \mathrm{L}$ nitrogen (N), 100-350 mg/L phosphate $\left(\mathrm{P}_{2} \mathrm{O}_{5}\right), 200-400 \mathrm{mg} / \mathrm{L}$ potassium oxide $\left(\mathrm{K}_{2} \mathrm{O}\right)$ ) and young seedlings were thinned when they reached the 3rd true leaf stage in order to have one plant per pot. The three fertilization treatments of the experiment were: i) control (only peat) without fertilization ii) inorganic fertilizer $15-5-20(2+8)$ at the dose of $330 \mathrm{Kg}$ / ha (half rate), and iii) inorganic fertilizer 15-5-20(2+8) at the dose of $660 \mathrm{Kg} / \mathrm{ha}$ (full rate). The inorganic fertilizer was uniformly mixed with peat substrate before pot filling and applied as basal dressing before sowing. The detailed composition of the applied fertilizer was as follows: $15 \%$ nitrogen $\left(7 \% \mathrm{NO}_{3}-\mathrm{N}\right.$ and $\left.8 \% \mathrm{NH}_{4}-\mathrm{N}\right), 5 \%$ phosphorus $\left(\mathrm{P}_{2} \mathrm{O}_{5}\right)$, $20 \%$ potassium $\left(\mathrm{K}_{2} \mathrm{O}\right), 2 \%$ magnesium $(\mathrm{MgO}), 8 \%$ sulphur $\left(\mathrm{SO}_{3}\right), 0.02 \%$ boron and $0.01 \%$ zinc.

Harvesting of plants was carried out at the end of the growing period (June 2016) and agronomic parameters were determined as described in the following section (see Section 2.1). After harvest, plants were separated into leaves (samples A, C and E for the control, half rate and full rate, respectively) and roots (samples B, D and F for the control, half rate and full rate, respectively). In contrast, roots were further cleaned with distilled water for the removal of substrate particles. Batch samples of plant tissues from both plant parts were used for the determination of chemical composition and bioactive properties. For this purpose, fresh samples of leaves and roots were stored at $-20{ }^{\circ} \mathrm{C}$ in air-sealed plastic bags, then lyophilised and pulverised to a powder, and finally stored at $-80{ }^{\circ} \mathrm{C}$ until chemical analysis.

\subsection{Agronomic parameters}

Fresh weight of leaves ( $\mathrm{g}$ /plant) and roots ( $\mathrm{g}$ /plant) of small burnet plants were measured on the day of harvest (27 June 2016). Moreover, on the same sampling date, chlorophyll content of leaves was determined by using the portable chlorophyll meter SPAD-502 (Konica Minolta Optics, Inc., Osaka, Japan).

\subsection{Extract preparation of plant material}

Plant extracts were prepared according to the methodology previously described by Bessada, Barreira, Barros, Ferreira, and Oliveira (2016) with some modifications. In brief, each sample (1 g) was extracted twice by stirring $\left(25{ }^{\circ} \mathrm{C}\right.$ at $\left.150 \mathrm{rpm}\right)$ with $30 \mathrm{~mL}$ of methanol/ water $(80: 20, v / v)$ for $1 \mathrm{~h}$, subsequently filtered through a Whatman No. 4 paper. After filtration, methanol was removed using a rotary evaporator (Büchi R-210, Flawil, Switzerland) and samples were frozen and lyophilized (FreeZone 4.5 model 7750031, Labconco, Kansas City, MO, USA).

\subsection{Phenolic compounds composition}

The extracts were re-dissolved in methanol/water (80:20, $v / v$, $10 \mathrm{mg} / \mathrm{mL}$ ) and filtered through a $0.22 \mu \mathrm{m}$ disposable LC filter disk. The phenolic compounds were evaluated using a Dionex Ultimate 3000 UPLC (Thermo Scientific, San Jose, CA, USA) and detection was carried out with a diode array detector (DAD) using 280, 330, and $370 \mathrm{~nm}$ as preferred wavelengths, coupled to an electrospray ionization mass spectrometry detector (ESI/MS) (API 3200 Qtrap, Applied Biosystems, Darmstadt, Germany), according to the conditions described by Bessada et al. (2016).

Phenolic compounds were identified out by comparison of retention times, UV-VIS and mass spectra, while standard compounds, reported data from the literature, and tentative identification through the fragmentation pattern were also used. The quantification was performed by applying a manual integration using baseline to valley integration mode with baseline projection. To quantify/estimate the identified compounds different individual calibration curves of phenolic standards were used and when a standard was not available to quantify/estimate a phenolic compound, a similar compound of the same phenolic group was used. The recorded peak areas were obtained at different wavelengths depending on the nature of the compounds ( $370 \mathrm{~nm}$ for flavonols glycoside derivatives and ellagic acid and derivatives; $280 \mathrm{~nm}$ for flavan-3-ols and hydrosoluble tannins; $330 \mathrm{~nm}$ for hydroxycinnamic acid). The results were expressed in $\mathrm{mg}$ per $\mathrm{g}$ of extract.

\subsection{Bioactive properties}

\subsubsection{Cytotoxic activity}

The cytotoxicity of the tested materials was evaluated using four tumor cell lines, namely HeLa (cervical carcinoma), HepG2 (hepatocellular carcinoma), MCF-7 (breast adenocarcinoma), NCI-H460 (nonsmall cell lung cancer), and non-tumour PLP2 (porcine liver cells) using a methodology previously described by Abreu et al. (2011) and using the sulforhodamine $\mathrm{B}$ assay. The results were expressed in $\mathrm{GI}_{50}$ values $(\mu \mathrm{g} / \mathrm{mL})$ which correspond to the concentration that inhibited cell growth by $50 \%$. Ellipticine was used as a positive control. 


\subsubsection{Antimicrobial activity}

Antimicrobial activity was determined using four Gram-positive bacteria: Staphylococcus aureus (ATCC 11632), Bacillus cereus (food isolate), Micrococcus flavus (ATCC 10240) and Listeria monocytogenes (NCTC 7973), four Gram-negative bacteria: Pseudomonas aeruginosa (ATCC 27853), Escherichia coli (ATCC 25922), Enterobacter cloacae (ATCC 35030) and Salmonella typhimurium (ATCC 13311), and six fungi: Aspergillus fumigatus (ATCC 9197), Aspergillus niger (ATCC 6275), Aspergillus ochraceus (ATCC 12066), Penicillium ochrochloron (ATCC 9112), Penicillium funiculosum (ATCC 36839) and Penicillium verrucosum var. cyclopium (food isolate) using the microdilution method according to the protocol described by Petropoulos, Fernandes, Barros et al. (2017). The microbial viability was assessed by microbial growth (MICs), minimal bactericidal concentration (MBC) and minimal fungicidal concentration (MFC). Streptomycin, ampicillin and ketoconazole (Sigma-Aldrich, St Louis, MO, USA) were used as positive controls.

\subsection{Statistical analysis}

For growth parameters, results were expressed as means \pm standard deviation (SD) of 15 replications $(n=15)$, while results of chemical composition and bioactive properties were expressed as means \pm SD of three samples $(n=3)$, each being assayed in triplicate. The statistical analysis was carried out by using SPSS v. 23.0 software and using the one-way analysis of variance (ANOVA), while means were compared with the Tukey's HSD test $(p<0.05)$.

\section{Results and discussion}

\subsection{Plant growth features}

Plant growth parameters (fresh weight of leaves and roots, and SPAD index) are presented in Table 1 . According to the results, fertilization regime had a significant $(\mathrm{P}<0.05)$ effect on leaves and fresh root biomass. For both parameters, the highest values were observed for the full fertilization rate followed by the half rate and the control treatment, while the biomass of leaves and roots ranged between 8.10 and $21.57 \mathrm{~g} /$ plant and $11.54-31.83 \mathrm{~g} /$ plant, respectively.

Similarly, the relative chlorophyll content of leaves was affected by fertilization regime (Table 1), and the greatest SPAD values were observed when the full fertilization rate was applied followed by the halfrate and the control treatment (SPAD index values of 35.40, 30.23, and 25.93, respectively). Moreover, a decreasing trend for the ratio of relative chlorophyll content/fresh weight with increasing fertilization rates was observed, which could be attributed to the better availability and uptake of nutrients from plants resulting in increased biomass without however increasing proportionally the total leaf area and

Table 1

Fresh weight of leaves and roots (g/plant) and chlorophyll content (SPAD index values) of Sanguisorba minor plants in relation to fertilization regime.

\begin{tabular}{lll}
\hline Samples & Fresh weight (g/plant) & Chlorophyll content (SPAD values) \\
\hline Leaves & \multicolumn{2}{l}{} \\
A & $8.10 \pm 0.66^{\mathrm{c}}$ & $25.93 \pm 1.11^{\mathrm{c}}$ \\
C & $14.07 \pm 1.38^{\mathrm{b}}$ & $30.23 \pm 1.59^{\mathrm{b}}$ \\
E & $21.57 \pm 3.93^{\mathrm{a}}$ & $35.40 \pm 1.31^{\mathrm{a}}$ \\
Roots & & \\
B & $11.54 \pm 3.46^{\mathrm{c}}$ & - \\
D & $20.08 \pm 4.21^{\mathrm{b}}$ & - \\
F & $31.83 \pm 4.74^{\mathrm{a}}$ & - \\
\hline
\end{tabular}

Different letters in the same column show significant difference between means of the same plant part (leaves: A, C, E and roots: B, D, F) according to Tukey's HSD test $(p<0.05)$; A, B: control without fertilization, C, D: inorganic fertilizer applied at the rate of $330 \mathrm{Kg} / \mathrm{ha}$, and $\mathrm{E}, \mathrm{F}$ : inorganic fertilizer applied at the rate of $660 \mathrm{Kg} / \mathrm{ha}$. consequently chlorophyll content. To the best of our knowledge, there are no reports regarding the effects of fertilization on $S$. minor biomass and chlorophyll content, while scarce literature reports exist regarding the effects of cultivation practices on growth and physiological characteristics of this wild edible herb. In a recent study, Karkanis et al. (2019) reported that the type of growth substrate (different ratios of peat and perlite) had a significant effect on leaves and stems biomass of $S$. minor plants with the highest values being recorded for plants grown in sole peat substrate in comparison to plants grown in peat and perlite mixtures. Moreover, considering that the existing reports refer to genetic material from wild ecotypes with great diversity among them, the effect of genotype on agronomic performance has to be considered since complementarity and intra- or inter-specific competition in diversified wild ecosystems may affect plant productivity and selection process in natural environments (Mahaut, Fort, Violle, \& Freschet, 2019).

\subsection{Phenolic compounds composition}

The detected compounds in leaves and roots of $S$. minor plants are presented in Table 2. The analysis revealed the presence of twenty-two compounds which were divided into three different classes, namely flavonoids, hydrolysable tannins and phenolic acids. Eleven of these compounds were detected in the leaves, fourteen in roots and seven were common in both plant parts, a result which indicates the significant variations in the profile of individual phenolic compounds among the studied parts (leaves and roots) (Table 2).

The characterization of $S$. minor phenolic compounds was performed by HPLC-DAD-ESI/MS and a typical chromatogram is presented in Fig. 1 (e.g. samples C and D). The data referring to retention times, $\lambda_{\max }$, pseudomolecular ion, main fragment ions in $\mathrm{MS}^{2}$, as well as to tentative identification and quantification of the phenolic compounds detected in the tested samples are presented in Table 2.

The detected flavonoids correspond to catechin and their oligomers (peaks 3, 6 and 8; $\lambda_{\max }$ around $279 \mathrm{~nm}$ and an $\mathrm{MS}^{2}$ fragment at $\mathrm{m} / \mathrm{z}$ 289), quercetin (peaks 15, 18, and 20; $\lambda_{\max }$ around $354 \mathrm{~nm}$ and an $\mathrm{MS}^{2}$ fragment at $m / z 301$ ) and kaempferol (peak 22; $\lambda_{\max }$ around $346 \mathrm{~nm}$ and an $\mathrm{MS}^{2}$ fragment at $m / z 285$ ), while peaks 1, 2, 5, 7 and 9-14 were identified as hydrolysable tannins, showing UV and MS fragmentation spectra relevant to galloyl and hexahydroxydiphenoyl (HHDP) derivatives. Regarding phenolic acids, compounds with peak numbers 16, 17, 19 and 21 were identified as ellagic acid derivatives, while peak number $\mathbf{4}$ was identified as $p$-coumaroylquinic acid. Of all the identified compounds, only peaks 6 and 21 were positively idenfied as catechin and ellagic acid, respectively, in comparision to the commercial standards. With the exception of compound 4 (p-coumaroylquinic acid), all the other phenolic compounds were previously reported in $S$. minor plant parts by Ayoub (2003), and Karkanis et al. (2019) who used the same genetic material (ecotype). Other authors also reported a similar phenolic composition, thus using an ethanolic extracts of $S$. officinalis (Gawron-Gzella et al., 2016; Tan et al., 2019).

The predominant phenolic compounds detected in leaves were sanguiin H-10, lambertianin C and pedunculagin (bis-HHDP-glucoside), followed by galloyl-HHDP-glucoside and quercetin-O-glucuronide. In contrast, roots had a different profile of phenolic compounds with (+)-catechin and B-type (epi)catechin dimer and tetramer being the prevailing compounds (Table 2). In general, roots contained higher amounts of total phenolic acids, total hydrolysable tannins and total flavonoids than leaves, which was reflected to the increased amount of total phenolic compounds by $35.2 \%, 183.8 \%$ and $84.7 \%$ for the control half-rate and full-rate treatments, respectively. According to ElMousallamy (2002) S. minor is a rich source of tannins and related compounds, while the aerial parts (leaves and stems) have a high flavonoid content (Cuccioloni et al., 2012; Karkanis et al., 2019). Moreover, several derivatives of gallic acid such as methyl glucoside gallates and gallic acid glucoside gallate have been previously detected in $S$. officinalis (Nonaka, Tanaka, Nita, \& Nishioka, 1982). Similarly, Ayoub 


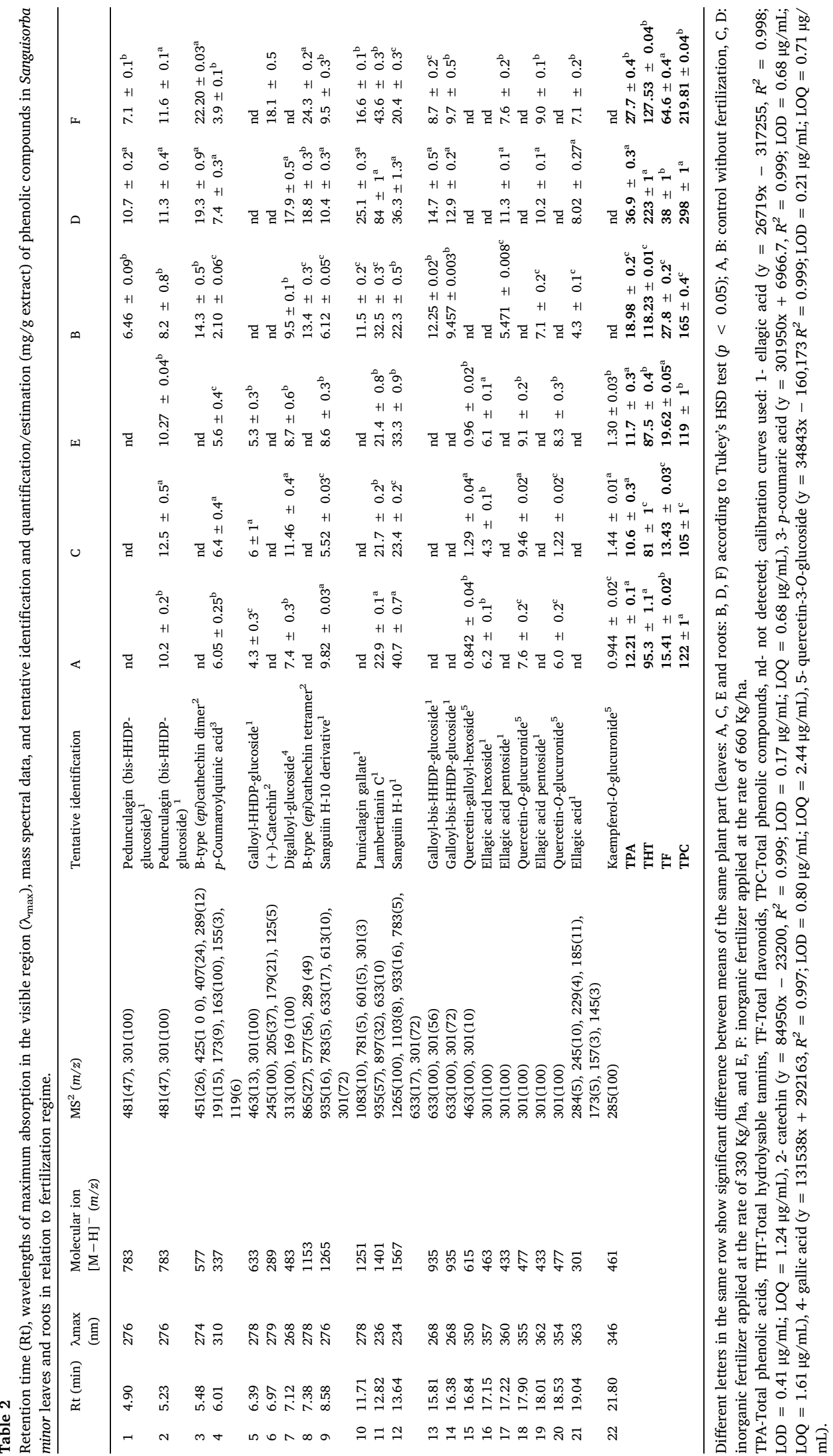



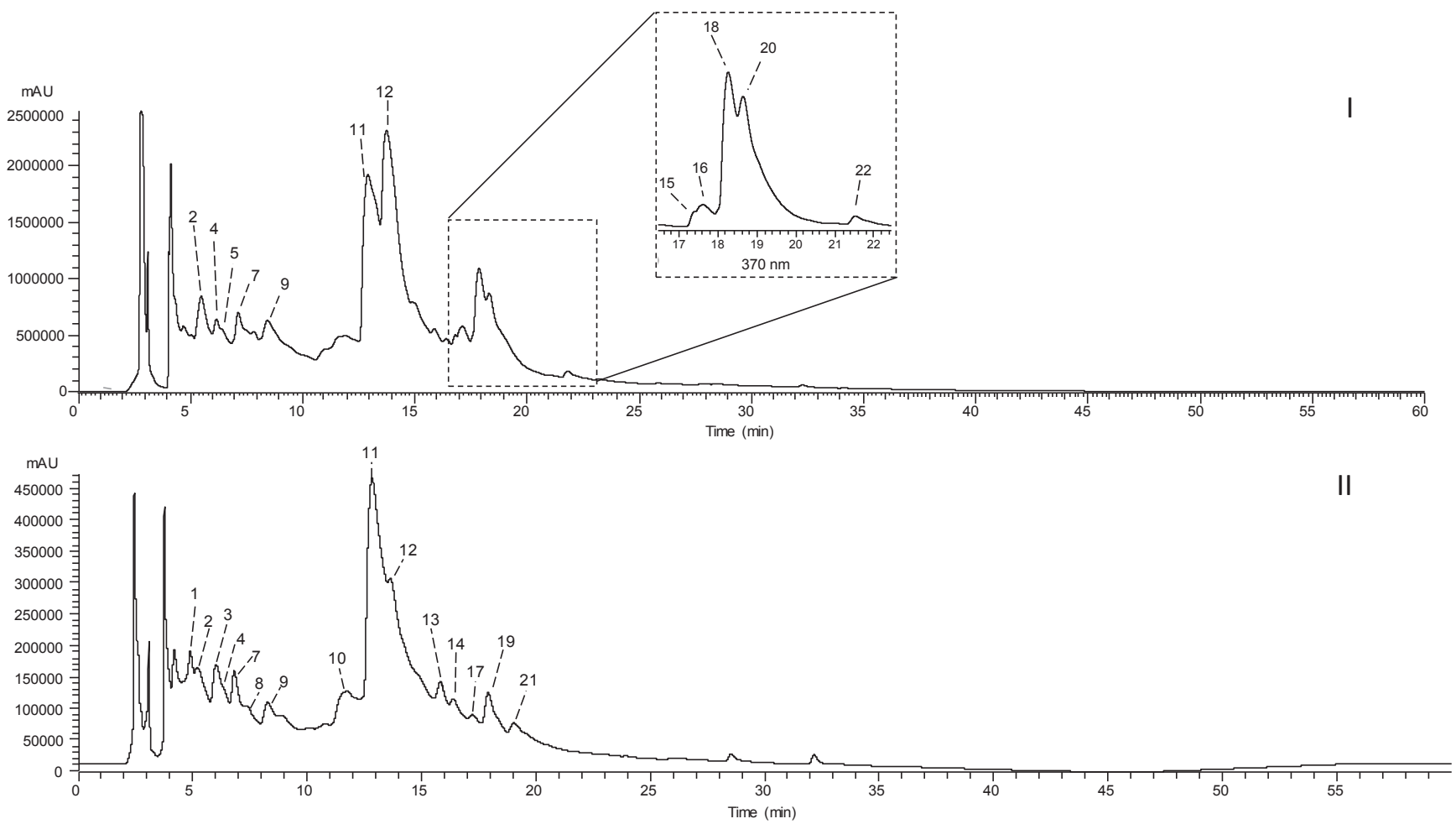

Fig. 1. Phenolic profile of Sanguisorba minor grown inorganic fertilizer at half rate (330 $\mathrm{kg} \mathrm{ha}^{-1}$ ) recorded at $280 \mathrm{~nm}$. I. Leaves (C); II. Roots (D). For peak, numbers refer to Table 2.

(2003) and Tan et al. (2019) isolated phenolic carboxylic acids and ellagic acid from $S$. minor and $S$. officinalis, respectively. It is also important to point out that the content of phenolic compounds in leaves and roots was lower than that reported previously by the authors (Karkanis et al., 2019) despite the similar genetic material used in both studies (the same population). These differences are probably due to the different growing conditions since in the study of Karkanis et al. (2019) plants were sown in winter (December), whereas in the current experiment sowing was carried out in the spring. In a recent study, Petropoulos, Fernandes, Vasileios et al. (2018) also revealed that the growing season might significantly affect the chemical composition of Cichorium spinosum leaves, including phenolic compounds content, suggesting that sowing in December resulted in higher total phenolic compounds content compared to sowing during autumn. Similar results were reported by Petropoulos, Fernandes, Karkanis et al. (2017) who apart from the growing season effect they also highlighted the significance of harvesting stage on phenolic compounds content. At the same time, Elgersma, Søegaard, and Jensen (2015) found a correlation between bioactive compounds content and harvesting date in various forage species, including $S$. minor.

Concerning the effects of fertilization regime on phenolic compounds composition, a variable effect was observed depending on the plant part as well as on the individual compound. In particular, the major compounds of leaves (peaks 11 and 12; lambertianin $C$ and sanguiin $\mathrm{H}-10$, respectively) did not increase by the application of fertilizers, whereas a contrasting effect was observed in roots where the half-rate treatment resulted in the highest content for both compounds. Moreover, the application of fertilizers did not have a significant effect on total phenolic acids content of leaves, whereas the same class of phenolic compounds was significantly increased in roots after the application of the half-rate regime $(330 \mathrm{~kg} / \mathrm{ha})$. A similar trend was observed for hydrolysable tannins where their content in leaves was the highest for the control treatment, since both the major compounds (peaks 11 and 12) were not affected by the tested fertilizer treatments, whereas in roots the half-rate treatment resulted in higher contents of these compounds compared to the full rate and the control treatment. Flavonoids content exhibited a different trend and the higher amount was observed when the full rate fertilizer treatment was applied, regardless of the plant part. Moreover, the increase of flavonoids content in leaves at the full rate regime was also reflected in total phenolic compounds content despite the highest amounts of hydrolysable tannins detected in the control treatment. In roots, the half-rate fertilizer treatment resulted in the highest total phenolic compounds content mostly due to the increase of hydrolysable tannins by $88.6 \%$ compared to the control treatment.

The effect of fertilizer application on phenolic compounds composition in wild edible plants has also been reported for Cichorium spinosum by Petropoulos, Fernandes, Vasileios et al. (2018), Petropoulos, Fernandes, Calhelha et al. (2019), where different amounts of ammonium and nitrate nitrogen were tested. According to Mollavali, Perner, Rohn, Hanschen, and Schwarz (2018), the increased amounts of $\mathrm{NH}_{4}-\mathrm{N}$ were associated with increased flavonols content and phenylalanine ammonia lyase activity which contribute to plant detoxification mechanisms. This finding agrees with the results of the present study where the applied fertilizer had a higher content of $\mathrm{NH}_{4}-\mathrm{N}$ than $\mathrm{NO}_{3}-\mathrm{N}$.

\subsection{Cytotoxic activity}

The cytotoxic effects of the studied extracts against the tested cell lines are presented in Table 3 . The extracts from the roots of the full fertilization rate treatment $(660 \mathrm{~kg} / \mathrm{ha})$ showed the highest activity against HeLa cell line $\left(\mathrm{GI}_{50}=55 \mu \mathrm{g} / \mathrm{mL}\right)$, followed by NCI-H460 $\left(\mathrm{GI}_{50}=65 \mu \mathrm{g} / \mathrm{mL}\right)$ and HepG2 $(92 \mathrm{mg} / \mathrm{mL})$, while both fertilizer treatments (half and full-rate) were effective against MCF-7 cell line $\left(\mathrm{GI}_{50}=67\right.$ and $71 \mu \mathrm{g} / \mathrm{mL}$ for half and full fertilization rate, respectively). Moreover, all the root samples showed toxic effects against the tested non-tumour PLP2 cell line, especially the control treatment were the lowest $\mathrm{GI}_{50}$ values were recorded $(231 \mathrm{mg} / \mathrm{mL})$.

The extracts of leaves exhibited lower activity against the HepG2 and NCI-H460 cell lines compared to the root extracts (Table 3). 
Table 3

Cytotoxicity of Sanguisorba minor $\left(\mathrm{GI}_{50}\right.$ values $\left.\mu \mathrm{g} / \mathrm{mL}\right)$ leaves and roots in relation to fertilization regime.

\begin{tabular}{|c|c|c|c|c|c|}
\hline \multirow[t]{2}{*}{ Samples } & \multirow{2}{*}{$\begin{array}{l}\text { Cytotoxicity to non-tumour cell } \\
\text { lines } \\
\text { PLP2 (porcine liver primary } \\
\text { culture) }\end{array}$} & \multicolumn{4}{|c|}{ Cytotoxicity to tumour cell lines } \\
\hline & & $\begin{array}{l}\text { HeLa (cervical } \\
\text { carcinoma) }\end{array}$ & HepG2 (hepatocellular carcinoma) & $\begin{array}{l}\text { MCF-7 (breast } \\
\text { carcinoma) }\end{array}$ & $\begin{array}{l}\text { NCI-H460 (non-small cell lung } \\
\text { cancer) }\end{array}$ \\
\hline A & $>400$ & $74 \pm 5^{b}$ & $110 \pm 5^{c}$ & $79 \pm 6^{\mathrm{b}}$ & $228 \pm 14^{\mathrm{b}}$ \\
\hline $\mathrm{C}$ & $>400$ & $70 \pm 2^{b}$ & $142 \pm 7^{b}$ & $83 \pm 4^{b}$ & $197 \pm 10^{\mathrm{c}}$ \\
\hline $\mathrm{E}$ & $>400$ & $99 \pm 5^{a}$ & $159 \pm 7^{a}$ & $142 \pm 6^{\mathrm{a}}$ & $293 \pm 21^{\mathrm{a}}$ \\
\hline B & $231 \pm 17^{\mathrm{c}}$ & $61 \pm 4^{\mathrm{a}}$ & $161 \pm 6^{\mathrm{a}}$ & $129 \pm 5^{a}$ & $81 \pm 3^{\mathrm{a}}$ \\
\hline $\mathrm{D}$ & $264 \pm 8^{b}$ & $63 \pm 4^{a}$ & $108 \pm 6^{b}$ & $67 \pm 2^{\mathrm{b}}$ & $79 \pm 4^{a}$ \\
\hline $\mathrm{F}$ & $291 \pm 10^{\mathrm{a}}$ & $55 \pm 6^{\mathrm{b}}$ & $92 \pm 9^{c}$ & $71 \pm 4^{b}$ & $65 \pm 6^{b}$ \\
\hline
\end{tabular}

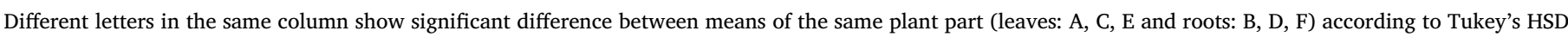

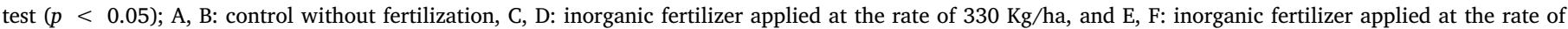
$660 \mathrm{Kg} / \mathrm{ha}$.



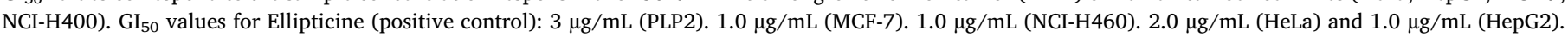

Moreover, the increase of fertilizer rates resulted in a decrease of cytotoxicity against all the tested tumour lines, whereas no toxic effects against the non-tumour cell line (PLP2) were observed. Cytotoxic effects against tumour cell lines have been previously reported for $S$. minor and Cuccioloni et al. (2012) suggested that $S$. minor ethanolic extracts were effective against plasmin-mediated cancer cell migration through the inhibitory effects of quercetin-3-glucuronide. In another study, Yoshida et al. (2019) suggested that ethanolic extracts from $S$. officinalis roots showed skin anti-wrinkling effects through the decrease of hyaluronan degradation and the increased synthesis of type I collagen. Moreover, triterpene glycosides isolated from $S$. officinalis roots exhibited significant cytotoxic activity against six tumour cell lines, including three cell lines that were also tested in the present study (MCF-7, HeLa, HepG2, SGC-7901, NCI-H460, and BGC-823) (Hu, Song, Li, \& Yang, 2015). In a recent study, Su, Guo, Yang, Kim, and Kim (2019) also observed that the ethyl acetate (EtOAc) from dried roots of S. officinalis inhibited the cytotoxic effects on HeLa cell lines induced by the pathogen Vibrio vulnificus.

Similarly, Choi et al. (2012) reported that the methanol extracts from $S$. officinalis exerted inhibitory effects against human prostate cancer cells (PC3), while Wang et al. (2012) found that S. officinalis exhibited antiproliferative properties by inducing apoptosis and inhibiting angiogenesis in two human breast cancer cell lines (MCF-7 and MDA-MB-231). According to Liu et al. (2016), root extracts from $S$. officinalis increased apoptotic effects of 5-fluorouracil against two colorectal cancer cell lines (HCT-116 and RKO), a synergistic action that was attributed to the presence of phenolic compounds such as gallic, catechin and ellagic acid. Other authors suggested ziyuglycoside II or polysaccharide fractions as the main bioactive compounds of $S$. officinalis with several health effects and significant antioxidant capacity (Lkhagvasuren \& Kim, 2019; Zhang et al., 2012; Zhu et al., 2013). These results highlight the need for further research to corroborate the associations of health effects with specific compounds as well as to elucidate the mechanisms behind these activities.

\subsection{Antimicrobial activity}

The results regarding the antibacterial activity of $S$. minor extracts are presented in Table 4. In most cases, the root extracts revealed a higher antibacterial capacity in comparison with leaves, especially against $S$. aureus, B. cereus, L. monocytogenes, and S. typhimurium, although even in the case of roots the extracts were less effective than positive controls. The only exception was observed in the case of $S$. typhimurium where root extracts from plants subjected to the half fertilization rate had lower MIC values than ampicillin. On the other hand, extracts from leaves were more effective than roots in the case of $M$. flavus and $P$. aeruginosa without however being more effective than positive controls.

Regarding the effect of the tested fertilization regime on antibacterial properties, extracts from leaves showed a variable response to fertilization rate. At the same time, no differences were observed against $L$. monocytogenes and E. cloacae between the tested treatments. Root extracts showed a more obvious response and extracts from plants grown under the half fertilization rate regime $(330 \mathrm{~kg} / \mathrm{ha})$ presented lower MIC and MBC values than the full fertilization rate $(660 \mathrm{~kg} / \mathrm{ha})$; except for the cases of $P$. aeruginosa, E. cloacae and $E$. coli where no differences between the tested treatments were observed. According to Janovská, Kubíková, and Kokoška (2003), ethanolic extracts of $S$. officinalis (aerial parts and roots) possess significant antibacterial activities against Bacillus cereus, Staphylococcus aureus, Pseudomonas aeruginosa and Candida albicans. Moreover, Karkanis et al. (2019) reported that root extracts from $S$. minor plants grown in different growth substrates revealed higher antibacterial against $B$. cereus, L. monocytogenes, E. coli, En. cloacae, and $S$. typhimurium compared to the roots and the positive controls (streptomycin and ampicillin), a difference that could be attributed to differences in the growing conditions compared to the present study. In a recent study, Su et al. (2019) also reported that bioactive compounds isolated from dried roots extracts of $S$. officinalis exhibited inhibitory effects against the Gram (-) bacterium Vibrio vulnificus in a dose dependent manner. Similarly to the present study, Zhu et al. (2019) observed that purified phenolic compounds extract (PE) from $S$. officinalis exhibited better activity against Gram (-) bacteria (Escherichia coli and Salmonella typhimurium) than against Gram (+) bacteria (S. aureus, L. monocytogenes and B. subtilis).

The antifungal activities of $S$. minor extracts (leaves and roots) are presented in Table 4. All the extracts revealed antifungal activity, except for the case of $A$. fumigatus where leaves from plants grown under the half or full fertilization rate did not show any activity, while none of the tested extracts was more effective than the positive control (ketoconazole). Leaves extracts from plants grown under the full fertilization rate regime presented the highest activity against $A$. ochraceus and $A$. niger without however being significantly different from root extracts of plants supplemented with fertilizers. Moreover, root extracts showed the highest efficacy against $P$. ochrochloron and, $P$. funicolosum, especially those extracts obtained from plants which received the full fertilization rate. The antifungal properties of $S$. minor have been previously reported by Karkanis et al. (2019) who recorded similar effects of extracts from the same plant parts (leaves and roots) against the same bacteria, although in many cases root extracts were more effective than the used positive controls. These differences could be attributed to different cultivation practices (growth substrates and fertilization regime), as well as to different growing conditions which may affect the biosynthesis of secondary metabolites and the bioactive properties of plant extracts (Petropoulos, Fernandes, Karkanis et al., 2018). 
Table 4

Antibacterial and antifungal activity of Sanguisorba minor leaves and roots concerning fertilization regime.

\begin{tabular}{|c|c|c|c|c|c|c|c|c|c|c|c|c|c|c|c|c|}
\hline \multirow[t]{2}{*}{ Samples } & \multicolumn{2}{|c|}{$\begin{array}{l}\text { S. aureus (ATCC } \\
\text { 11632) }\end{array}$} & \multicolumn{2}{|c|}{$\begin{array}{l}\text { B. cereus(food } \\
\text { isolate) }\end{array}$} & \multicolumn{2}{|c|}{$\begin{array}{l}\text { M. flavus (ATCC } \\
10240)\end{array}$} & \multicolumn{2}{|c|}{$\begin{array}{l}\text { L. monocytogenes (NCTC } \\
7973 \text { ) }\end{array}$} & \multicolumn{2}{|c|}{$\begin{array}{l}\text { P. aeruginosa } \\
\text { (ATCC 27853) }\end{array}$} & \multicolumn{2}{|c|}{$\begin{array}{l}\text { S. typhimurium (ATCC } \\
\text { 13311) }\end{array}$} & \multicolumn{2}{|c|}{$\begin{array}{l}\text { E. cloacae (ATCC } \\
35030 \text { ) }\end{array}$} & \multicolumn{2}{|c|}{$\begin{array}{l}\text { E. coli (ATCC } \\
\text { 25922) }\end{array}$} \\
\hline & MIC & $\mathrm{MBC}$ & MIC & $\mathrm{MBC}$ & MIC & MBC & MIC & MBC & MIC & MBC & MIC & MBC & MIC & MBC & MIC & MBC \\
\hline A & 2.31 & 4.61 & 0.88 & 1.75 & 0.44 & 0.88 & 2.31 & 4.61 & 0.44 & 0.88 & 1.15 & 2.31 & 1.15 & 2.31 & 1.15 & 2.31 \\
\hline $\mathrm{C}$ & 2.31 & 4.61 & 0.58 & 1.15 & 1.15 & 2.31 & 2.31 & 4.61 & 0.58 & 1.15 & 1.75 & 3.50 & 1.15 & 2.31 & 1.15 & 2.31 \\
\hline $\mathrm{E}$ & 1.15 & 2.31 & 0.88 & 1.75 & 0.44 & 0.88 & 2.31 & 4.61 & 0.88 & 1.75 & 2.31 & 4.62 & 1.15 & 2.31 & 2.31 & 4.61 \\
\hline B & 0.58 & 1.15 & 0.88 & 1.75 & 0.58 & 1.15 & 0.88 & 1.75 & 0.88 & 1.75 & 1.75 & 3.50 & 1.15 & 2.31 & 1.15 & 2.31 \\
\hline $\mathrm{D}$ & 0.88 & 1.75 & 0.44 & 0.88 & 0.58 & 1.15 & 0.44 & 0.88 & 0.88 & 1.75 & 0.22 & 0.44 & 1.15 & 2.31 & 1.15 & 2.31 \\
\hline $\mathrm{F}$ & 1.15 & 2.31 & 0.88 & 1.75 & 1.15 & 2.31 & 1.75 & 3.50 & 0.88 & 1.75 & 1.75 & 3.50 & 1.15 & 2.31 & 1.15 & 2.31 \\
\hline Streptomycin & 0.006 & 0.012 & 0.10 & 0.20 & 0.20 & 0.30 & 0.20 & 0.30 & 0.025 & 0.05 & 0.20 & 0.30 & 0.003 & 0.006 & 0.10 & 0.20 \\
\hline Ampicillin & 0.012 & 0.025 & 0.25 & 0.40 & 0.30 & 0.30 & 0.40 & 0.50 & 0.05 & 0.10 & 0.30 & 0.40 & 0.006 & 0.012 & 0.20 & nd \\
\hline \multirow[t]{2}{*}{ Samples } & \multicolumn{2}{|c|}{$\begin{array}{l}\text { A. fumigatus (ATCC } \\
\text { 9197) }\end{array}$} & \multicolumn{3}{|c|}{$\begin{array}{l}\text { A. ochraceus (ATCC } \\
\text { 12066) }\end{array}$} & \multicolumn{2}{|c|}{$\begin{array}{l}\text { A. niger (ATCC } \\
6275)\end{array}$} & \multicolumn{3}{|c|}{$\begin{array}{l}\text { P. ochrochloron (ATCC } \\
9112 \text { ) }\end{array}$} & \multicolumn{2}{|c|}{$\begin{array}{l}\text { P. funiculosum(ATCC } \\
\text { 36839) }\end{array}$} & \multicolumn{4}{|c|}{$\begin{array}{l}\text { P. verrucosum var. cyclopium } \\
\text { (food isolate) }\end{array}$} \\
\hline & MIC & MFC & \multicolumn{2}{|c|}{ MIC } & MFC & MIC & MFC & MIC & \multicolumn{2}{|c|}{ MFC } & MIC & MFC & MIC & \multicolumn{3}{|c|}{ MFC } \\
\hline A & 2.50 & 5.00 & \multicolumn{2}{|c|}{1.25} & 2.50 & 2.50 & 5.00 & 2.50 & \multicolumn{2}{|c|}{5.00} & 1.25 & 2.50 & 2.50 & \multicolumn{3}{|c|}{5.00} \\
\hline $\mathrm{C}$ & nd & nd & \multicolumn{2}{|c|}{2.50} & 5.00 & 2.50 & 5.00 & nd & \multicolumn{2}{|c|}{ nd } & 2.50 & 5.00 & 2.50 & \multicolumn{3}{|c|}{5.00} \\
\hline E & nd & nd & \multicolumn{2}{|c|}{0.63} & 1.25 & 0.63 & 1.25 & nd & \multicolumn{2}{|c|}{ nd } & 0.63 & 1.25 & 0.63 & \multicolumn{3}{|c|}{1.25} \\
\hline B & 2.50 & 5.00 & \multicolumn{2}{|c|}{1.25} & 2.50 & 2.50 & 5.00 & 2.50 & \multicolumn{2}{|c|}{5.00} & 1.25 & 2.50 & 2.50 & \multicolumn{3}{|c|}{5.00} \\
\hline D & 1.25 & 2.50 & & & 1.25 & 0.63 & 1.25 & 1.25 & & & 0.63 & 1.25 & 0.63 & & 1.25 & \\
\hline $\mathrm{F}$ & 1.25 & 2.50 & & & 1.25 & 0.63 & 1.25 & 1.25 & & & 0.63 & 1.25 & 0.63 & & 1.25 & \\
\hline Ketoconazole & 0.20 & 0.50 & & & 0.20 & 0.20 & 0.50 & 0.20 & & & 0.15 & 0.20 & 0.20 & & 0.50 & \\
\hline
\end{tabular}

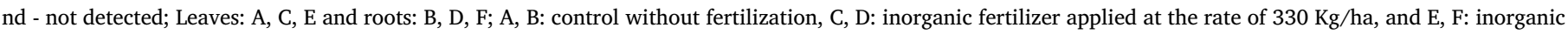

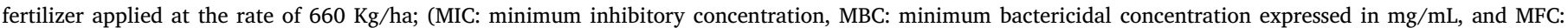
minimum fungicidal concentration expressed in $\mathrm{mg} / \mathrm{mL}$ ).

Moreover, in the study of Gatto, Ippolito, Sergio, and Di Venere (2016) it was reported that the extracts from the $S$. minor showed strong inhibitory activity against Aspergillus niger, Monilinia laxa, Penicillium digitatum and $P$ italicum and reduced the growth of $B$. cinerea probably due to the presence of phenolic compounds such as caffeic acid derivatives and various flavonoids.

\section{Conclusion}

Our results revealed that the full fertilizer rate (rate of $660 \mathrm{Kg} / \mathrm{ha}$ ) improved the content of phenolic compounds, and consequently, the cytotoxic effects against tumour cell lines and antimicrobial properties. Furthermore, extracts from the roots revealed higher antimicrobial and cytotoxic capacity, whereas extracts from leaves shown to be less toxic against non-tumour cell lines. These results could be related to the higher hydrolysable tannins, flavonoids and phenolic acids content present in roots extracts when compared with the aerial parts of the plant. Considering the extensive use of the small burnet in traditional medicine, the increase of the bioactive compounds, mainly the phenolic compounds content, through the modification of the growth conditions could expand its commercial value. Additionally, the commercial cultivation of the species could fulfill the market needs for natural bioactive compounds with further use in pharmaceutical and medicinal applications without compromising the conservation of wild populations and increasing genetic erosion due to irrational harvesting of wild plants.

\section{CRediT authorship contribution statement}

Tiane C. Finimundy: Methodology, Investigation, Writing - original draft. Anestis Karkanis: Conceptualization, Methodology, Writing - original draft. Ângela Fernandes: Methodology, Writing original draft. Spyridon A. Petropoulos: Conceptualization, Methodology, Writing - review \& editing. Ricardo Calhelha: Methodology. Jovana Petrović: Investigation, Methodology. Marina Soković: Investigation, Methodology. Eduardo Rosa: Writing - review \& editing. Lillian Barros: Conceptualization, Methodology, Writing original draft. Isabel C.F.R. Ferreira: Conceptualization, Methodology,
Writing - review \& editing.

\section{Declaration of Competing Interest}

The authors declare that they have no known competing financial interests or personal relationships that could have appeared to influence the work reported in this paper.

\section{Acknowledgements}

The authors are grateful to the Foundation for Science and Technology (FCT, Portugal) for financial support through national funds FCT/MCTES to CIMO (UIDB/00690/2020) and CITAB (UID/ AGR/04033/2019). L. Barros, A. Fernandes and R. C. Calhelha also thank the national funding by FCT - Foundation for Science and Technology, P.I., through the institutional scientific employment program-contract for their contracts. This work was also supported by European Investment Funds by FEDER/COMPETE/POCI-Operacional Competitiveness and Internacionalizaon Programme, under Project POCI-01-0145-FEDER-006958. The authors are also grateful to FEDERInterreg España-Portugal programme for financial support through the project 0377_Iberphenol_6_E.

\section{References}

Abreu, R. M. V., Ferreira, I. C. F. R., Calhelha, R. C., Lima, R. T., Vasconcelos, M. H., Adega, F., ... Queiroz, M. J. R. P. (2011). Anti-hepatocellular carcinoma activity using human HepG2 cells and hepatotoxicity of 6-substituted methyl 3-aminothieno[3,2-b] pyridine-2- carboxylate derivatives: In vitro evaluation, cell cycle analysis and QSAR studies. European Journal of Medicinal Chemistry, 46(12), 5800-5806. https://doi.org/ 10.1016/j.ejmech.2011.09.029.

Ayoub, N. A. (2003). Unique phenolic carboxylic acids from Sanguisorba minor. Phytochemistry, 63(4), 433-436. https://doi.org/10.1016/S0031-9422(03)00198-5.

Azimi, R., Heshmati, G. A., Kianian, M. K., \& Jafari, S. H. (2016). Investigating the germination characteristics of Poterium sanguisorba seeds under the influence of thermal treatments for pasture establishment. Journal of Rangeland Science, 6(1), 53-62.

Bedoya, L. M., Sanchez-Palomino, S., Abad, M. J., Bermejo, P., \& Alcami, J. (2001). AntiHIV activity of medicinal plant extracts. Journal of Ethnopharmacology, 77(1), 113-116. https://doi.org/10.1016/S0378-8741(01)00265-3.

Bessada, S. M. F., Barreira, J. C. M., Barros, L., Ferreira, I. C. F. R., \& Oliveira, M. B. P. P. (2016). Phenolic profile and antioxidant activity of Coleostephus myconis (L.) Rchb.f.: 
An underexploited and highly disseminated species. Industrial Crops and Products, 89, 45-51. https://doi.org/10.1016/j.indcrop.2016.04.065.

Burmeier, S., Donath, T. W., Otte, A., \& Eckstein, R. L. (2010). Rapid burial has differential effects on germination and emergence of small- and large-seeded herbaceous plant species. Seed Science Research, 20(3), 189-200. https://doi.org/10.1017/ S0960258510000127.

Choi, E. S., Kim, J. S., Kwon, K. H., Kim, H. S., Cho, N. P., \& Cho, S. D. (2012). Methanol extract of Sanguisorba officinalis L. with cytotoxic activity against PC3 human prostate cancer cells. Molecular Medicine Reports, 6(3), 670-674. https://doi.org/10.3892/ mmr.2012.949.

Cuccioloni, M., Bonfili, L., Mozzicafreddo, M., Cecarini, V., Eleuteri, A. M., \& Angeletti, M. (2012). Sanguisorba minor extract suppresses plasmin-mediated mechanisms of cancer cell migration. Biochimica et Biophysica Acta - General Subjects, 1820(7), 1027-1034. https://doi.org/10.1016/j.bbagen.2012.02.002.

De Lillis, M., Manes, F., \& Tufaro, F. (2005). Root plasticity in Mediterranean herbaceous species. Plant Biosystems, 139(2), 214-221. https://doi.org/10.1080/ 11263500500160542 .

Elgersma, A., Søegaard, K., \& Jensen, S. K. (2015). Interrelations between herbage yield, $\alpha$-tocopherol, $\beta$-carotene, lutein, protein, and fiber in non-leguminous forbs, forage legumes, and a grass-clover mixture as affected by harvest date. Journal of Agricultural and Food Chemistry, 63(2), 406-414. https://doi.org/10.1021/jf503658n.

El-Mousallamy, A. M. D. (2002). Polyphenols of Egyptian Rosaceae plants-two new flavonoid glycosides from Sanguisorba minor Scop. Die Pharmazie, 57(10), 702-704.

Gatto, M. A., Ippolito, A., Sergio, L., \& Di Venere, D. (2016). Extracts from wild edible herbs for controlling postharvest rots of fruit and vegetables. Acta Horticulturae (pp 349-354). Leuven, Belgium: International Society for Horticultural Science (ISHS). https://doi.org/10.17660/ActaHortic.2016.1144.51.

Gawron-Gzella, A., Witkowska-Banaszczak, E., Bylka, W., Dudek-Makuch, M., Odwrot, A., \& Skrodzka, N. (2016). Chemical composition, antioxidant and antimicrobial activities of Sanguisorba officinalis L. extracts. Pharmaceutical Chemistry Journal, 50(4), 244-249. https://doi.org/10.1007/s11094-016-1431-0.

Hu, J., Song, Y., Li, H., \& Yang, B. (2015). Cytotoxic triterpene glycosides from the roots of Sanguisorba officinalis. Archives of Pharmacal Research, 38, 984-990. https://doi. org /10.1007/s12272-014-0477-3.

Janovská, D., Kubíková, K., \& Kokoška, L. (2003). Screening for antimicrobial activity of some medicinal plants species of traditional Chinese medicine. Czech Journal of Food Sciences, 21(3), 107-110.

Karkanis, A. C., Fernandes, A., Vaz, J., Petropoulos, S., Georgiou, E., Ciric, A., ... Ferreira, I. (2019). Chemical composition and bioactive properties of Sanguisorba minor Scop. under Mediterranean growing conditions. Food and Function, 10(3), 1340-1351. DOI:10.1039/c8fo02601g.

Karkanis, A., Vellios, E., Thomaidis, T., Bilalis, D., Efthimiadou, A., \& Travlos, I. (2014). Phytochemistry and biological properties of burnet weed (Sanguisorba spp.): A review. Notulae Botanicae Horti Agrobotanici Cluj-Napoca, 6(4), 395-398. https://doi. org/10.1583/nsb649471.

Lenzi, A., Orlandini, A., Bulgari, R., Ferrante, A., \& Bruschi, P. (2019). Antioxidant and mineral composition of three wild leafy species: A comparison between microgreens and baby greens. Foods, 8(487), 1-19. https://doi.org/10.3390/foods8100487.

Liu, M. P., Liao, M., Dai, C., Chen, J. F., Yang, C. J., Liu, M., ... Yao, M. C. (2016). Sanguisorba officinalis L synergistically enhanced 5-fluorouracil cytotoxicity in colorectal cancer cells by promoting a reactive oxygen species-mediated, mitochondriacaspase-dependent apoptotic pathway. Scientific Reports, 6(34245), 1-14. https://doi. org/10.1038/srep34245.

Lkhagvasuren, K., \& Kim, J. K. (2019). Ziyuglycoside II induces caspases-dependent and caspases-independent apoptosis in human colon cancer cells. Toxicology in Vitro, 59, 255-262. https://doi.org/10.1016/j.tiv.2019.04.028.

Mahaut, L., Fort, F., Violle, C., \& Freschet, G. T. (2019). Multiple facets of diversity effects on plant productivity: Species richness, functional diversity, species identity and intraspecific competition. Functional Ecology, 34(1), 287-298. https://doi.org/10. 1111/1365-2435.13473.

Meng, X. X., Xian, Y. F., Xiang, L., Zhang, D., Shi, Y. H., Wu, M. L., ... Sun, W. (2018). Complete chloroplast genomes from Sanguisorba: Identity and variation among four species. Molecules, 23(9), 1-13. https://doi.org/10.3390/molecules23092137.

Mollavali, M., Perner, H., Rohn, S., Hanschen, F. S., \& Schwarz, D. (2018). Nitrogen form and mycorrhizal inoculation amount and timing affect flavonol biosynthesis in onion (Allium cepa L.). Mycorrhiza, 28, 59-70. https://doi.org/10.1007/s00572-0170799-3.

Nonaka, G., Tanaka, T., Nita, M., \& Nishioka, I. (1982). A dimeric hydrolyzable tannin, sanguiin H-6 from Sanguisorba officinalis L. Retrieved from Chemical Pharmaceutical Bulletin, 30(6), 2255-2257. http://www.mendeley.com/research/geology-volcanichistory-eruptive-style-yakedake-volcano-group-central-japan/.

Petropoulos, S., Fernandes, Â., Barros, L., Ciric, A., Sokovic, M., \& Ferreira, I. C. F. R. (2017). The chemical composition, nutritional value and antimicrobial properties of Abelmoschus esculentus seeds. Food and Function, 8(12), 4733-4743. https://doi.org/ 10.1039/c7fo01446e.

Petropoulos, S. A., Fernandes, Â., Calhelha, R. C., Di Gioia, F., Kolovou, P., Barros, L., \& Ferreira, I. C. F. R. (2019). Chemical composition and bioactive properties of Cichorium spinosum L. in relation to nitrate/ammonium nitrogen ratio. Journal of the Science of Food and Agriculture, 99, 6741-6750. https://doi.org/10.1002/jsfa.9956.

Petropoulos, S., Fernandes, Â., Karkanis, A., Antoniadis, V., Barros, L., \& Ferreira, I. C. F. R. (2018). Nutrient solution composition and growing season affect yield and chemical composition of Cichorium spinosum plants. Scientia Horticulturae, 231, 97-107. https://doi.org/10.1016/j.scienta.2017.12.022.

Petropoulos, S., Fernandes, Â., Karkanis, A., Ntatsi, G., Barros, L., \& Ferreira, I. (2017). Successive harvesting affects yield, chemical composition and antioxidant activity of Cichorium spinosum L. Food Chemistry, 237, 83-90. https://doi.org/10.1016/j. foodchem.2017.05.092.

Petropoulos, S. A, Fernandes, Â., Tzortzakis, N., Sokovic, M., Ciric, A., Barros, L., \& Ferreira, I. C. F. R. (2019). Bioactive compounds content and antimicrobial activities of wild edible Asteraceae species of the Mediterranean flora under commercial cultivation conditions. Food Research International, 119, 859-868. https://doi.org/10. 1016/j.foodres.2018.10.069.

Petropoulos, S. A., Fernandes, Â., Vasileios, A., Ntatsi, G., Barros, L., \& Ferreira, I. C. F. R. (2018). Chemical composition and antioxidant activity of Cichorium spinosum L. leaves in relation to developmental stage. Food Chemistry, 239, 946-952. https://doi. org/10.1016/j.foodchem.2017.07.043.

Petropoulos, S. A., Karkanis, A., Martins, N., \& Ferreira, I. C. F. R. (2016). Phytochemical composition and bioactive compounds of common purslane (Portulaca oleracea L.) as affected by crop management practices. Trends in Food Science \& Technology, 55 1-10. https://doi.org/10.1016/j.tifs.2016.06.010.

Romojaro, A., Sanchez-Bel, P., Serrano, M., \& Pretel, M. T. (2013). Wild edible plants as potential antioxidants in vegetables oils. Journal of Chemistry, 2013(457902), 1-4. https://doi.org/10.1155/2013/457902.

Snowball, R., D'Antuono, M. F., Cohen, B. J., Gajda, K., \& Bennett, R. (2010). The value of germplasm nurseries in selecting species for field evaluation. Crop and Pasture Science, 61(12), 957-969. https://doi.org/10.1071/CP10126.

Su, X. D., Guo, R. H., Yang, S. Y., Kim, Y. H., \& Kim, Y. R. (2019). Anti-bacterial effects of components from Sanguisorba officinalis L. on Vibrio vulnificus and their soluble epoxide hydrolase inhibitory activity. Natural Product Research, 33(23), 3445-3449. https://doi.org/10.1080/14786419.2018.1478825.

Tan, Y. H., Shudo, T., Yoshida, T., Sugiyama, Y., Si, J. Y., Tsukano, C., ... Kakizuka, A. (2019). Ellagic acid, extracted from Sanguisorba officinalis, induces G1 arrest by modulating PTEN activity in B16F10 melanoma cells. Genes to Cells, 24, 688-704. https://doi.org/10.1111/gtc.12719.

Wang, Z., Loo, W. T. Y., Wang, N., Chow, L. W. C., Wang, D., Han, F., ... Chen, J.-P. (2012). Effect of Sanguisorba officinalis L on breast cancer growth and angiogenesis. Expert Opinion on Therapeutic Targets, 16(sup1), S79-S89. https://doi.org/10.1517/ 14728222.2011 .642371$.

Yoshida, H., Yamazaki, K., Komiya, A., Aoki, M., Kasamatsu, S., Murata, T., ... Takahashi, Y. (2019). Inhibitory effects of Sanguisorba officinalis root extract on HYBID (KIAA1199)-mediated hyaluronan degradation and skin wrinkling. International Journal of Cosmetic Science, 41(1), 12-20. https://doi.org/10.1111/ics.12505.

Zhang, L., Koyyalamudi, S. R., Jeong, S. C., Reddy, N., Smith, P. T., Ananthan, R., \& Longvah, T. (2012). Antioxidant and immunomodulatory activities of polysaccharides from the roots of Sanguisorba officinalis. International Journal of Biological Macromolecules, 51(5), 1057-1062. https://doi.org/10.1016/j.ijbiomac.2012.08. 019.

Zhu, H. lin, Chen, G., Chen, S. ni, Wang, Q. rui, Wan, L., \& Jian, S. ping. (2019). Characterization of polyphenolic constituents from Sanguisorba officinalis L. and its antibacterial activity. European Food Research and Technology, 245(7), 1487-1498. DOI:10.1007/s00217-019-03276-2.

Zhu, X., Wang, K., Zhang, K., Huang, B., Zhang, J., Zhang, Y., ... Zhou, F. (2013). Ziyuglycoside II inhibits the growth of human breast carcinoma MDA-MB-435 cells via cell cycle arrest and induction of apoptosis through the mitochondria dependent pathway. International Journal of Molecular Sciences, 14(9), 18041-18055. https:// doi.org/10.3390/ijms140918041. 